\title{
Practice and Factors Influencing Partograph Utilization on the Delivery of nursing care: An analytical Cross - Sectional Study among Nurses in Singida, Tanzania
}

Dedius E. Peter ( $\square$ peterdedius@gmail.com )

the University of Dodoma

Walter C. Millanzi

the University of Dodoma College of Health Sciences

Angelina A. Joho

the University of Dodoma College of Health Sciences

Research article

Keywords: practice, utilization, partograph, nurses and nursing care

Posted Date: September 21st, 2020

DOI: https://doi.org/10.21203/rs.3.rs-70920/v1

License: (c) (1) This work is licensed under a Creative Commons Attribution 4.0 International License.

Read Full License 


\section{Abstract \\ Background}

Partograph is the graphic recording for labour management and monitoring of pregnant women in labour pain. The well-plotted data allow the nurse to recognize any abnormal conditions earlier and decide to employ proper actions to the particular pregnant mother in labour pain during the delivery of nursing care. However, its uses have been recommended by WHO among nurses around the globe but it is not fully utilized. This study aimed to determine the level of practice and factors influencing partograph utilization among nurses in Singida, Tanzania.

\section{Methods}

Analytical cross sectional study was conducted involving 150 nurses randomly selected from Sokoine health center and Singida Regional Referral Hospital in Singida municipality, Tanzania from January to February 2020. A self-administered structured questionnaire on partograph use to deliver maternal care among pregnant women was the main data collection tool. The Statistical Package for Social Science (SPSS) software program version 23 was used for data entry, screening, processing, and analysis. Both descriptive and inferential statistics were employed in which findings were presented in tables.

\section{Results}

Out of 150 nurse midwives $58.7 \%(n=88)$ were females. Only $38.7 \%(n=58)$ of the study respondents had a high level of practice on the utilization of partograph during labour monitoring. Their levels of education were identified to be a protective factor because those who had University education were more times likely to practice using partograph when delivering care compared to other lower education levels $(A O R=16.757 ; 95 \% \mathrm{Cl}: 6.394 ; 43.915 ; \mathrm{p}<0.01)$. Also, their professional qualifications were discovered to be a protective factor because nurse officers and midwives officers were more times likely to practice using partograph as compared to other professional qualifications $(A O R=8.323 ; p=0.004 ; 95 \% \mathrm{Cl}: 0.098$; $0.642)$.

\section{Conclusion}

This study found that many nurses in Singida municipality had a low level of practice in utilizing partograph when delivering of health care among patients. Continuous and formal supportive supervisions and on job training at national and health facilities need to be emphasized and adhered to promote quality of health services by use of partograph and cost-effective maternal and newborns health. 


\section{Background}

Many women who become pregnant globally suffer much during the perinatal period. Pregnant women in the world who die due to pregnancy-induced complications were estimated to be 303,000 deaths yielding a maternal mortality ratio (MMR) of 2016 deaths per 100,000 live births (1). According to WHO which reported that these deaths decreased worldwide to estimate of 44 percent from 1990 to 2015 (2). Approximately 289,000 deaths occurred in 2013 and $99 \%$ of deaths occurred in Asian and African countries which are not developed and more than half happened in the African continent. Furthermore, data showed that African countries had 179000 (62\%) of global deaths and southern part of Asia had 69 $000(24 \%)$ maternal mortality (3).

Philpott and Castle initiated uses of partograph in 1972 and later on in 1988 were modified and initiated to be used globally in the health care setting for labour monitoring and management (4).The WHO emphasized the uses of partograph for monitoring progress of labour, fetal and maternal conditions as well as reducing labour complications which were a significant strategy to reduce both maternal and fetal mortality in the globe (5). Although WHO recommended the uses of the partograph to monitor progress of labour, fetal and maternal conditions in all settings routinely but it is not implemented as it should be to aid in guiding in early decision making (6).

The African countries still face the same problem because studies done by(7)data showed that maternal complications were estimated to be $0.34 \%$ and neonatal deaths approximated to be $2.1 \%$ in Rwanda. Data uncovered that $36.6 \%$ of health care providers were not trained on labour management by using partograph during delivery. Although, partograph is not a complex and expensive tool which can be used to reduce fetal and maternal mortality as well as complications due to prolonged labour or obstructed labour it is not used accordingly. Caregivers may not use the partograph only if they have inadequate knowledge and cannot know the reasons for utilizing it properly (5).

According to (8)findings showed that nurses who had an average understanding of the use of partograph were about $57.5 \%$ and $25 \%$ were knowledgeable while $17.5 \%$ were not knowledgeable, ultimately they commented that they had low knowledge regarding the use of partograph. So there was a need for ongoing training and close supervision among nurses to increase the quality use of partograph in hospitals. According to (9), he recommended that a lack of detailed knowledge of the partograph use, inadequate training, and poor policy cause poor ineffective use of partograph. To solve this problem periodic training and mandatory institutional policy should be considered on partograph utilization.

Furthermore, results from a study done by (5)showed that nurses who were at maternity department perceived that partograph use consumes much time and needs on-going training because some did not receive any training on partograph utilization since they were employed. He recommended that policymakers and nursing administrators should ensure that all qualified nurses use the partograph in the care of women in labour (5). Tanzania faces the same challenge of using partograph because data showed that poor utilization of partograph was observed at Mbeya Regional Referral Hospital, Geita Regional Referral Hospital, and Kitete Regional Referral Hospital(10). 
Despite the strategies of the ministry of health to emphasize on wisely use of partograph on the delivery of health care among pregnant women, there is persistent of maternal and fetal complications such as prolonged labour, uterine rupture, hemorrhage, birth asphyxia, and neonatal sepsis respectively in Tanzania(10).

Therefore, this study aimed to investigate the level of practice and factors influencing partograph utilization to raise the provision of health care among nurses. The significance of this study is that the data should be used as the baseline data for conducting large scale research on partograph utilization in the Singida region. Also, the results would help to decrease the number of deaths in pregnant women because proper use of partograph would help to detect abnormal markers in the progress of labour earlier and proper management to be initiated to save the life of the patient.

\section{Methods}

\section{Study design and Setting}

The analytical cross sectional study was conducted from January to June 2020 in Singida Municipality, Tanzania. The municipality is subdivided into sixteen wards such as Ipembe, Kindai, Majengo, Mandewa, Minga, Misuna, Mitunduruni, Mtamaa, Mtipa, Mughanga, Mungumaji, Mwankoko, Uhamaka, Unyambwa, Unyamikumbi, and Utemini. Singida Region is found in the central part of Tanzania. Basing on august 26, 2012 national census, Singida municipality had a population of 150,379 (Males $=73,484$, Females $=$ $76,895)$ with density of $208.7 / \mathrm{km}^{2}$ from $721 \mathrm{~km}^{2}$ total area of the municipality. Health facilities found in Singida municipality are both private and public health facilities such as Singida Region Referral Hospital, Sokoine Health Center, Mico Health Center Ginnery, Faraja Health Center, Singida Prisons Dispensary, Mafimbo dispensary, Police Dispensary, and Pride women's clinic. This research was done at Singida regional referral hospital and Sokoine Health center found in Singida Municipality, Tanzania.

\section{Study population}

The population understudy were 150 nurses who were working in maternity wards in Singida region after providing informed consent to participate in the study

\section{Inclusion criteria}

These are the criteria that characterize who is included in the study population (11). The study inclusion criteria were; qualified nurses who had worked in maternity at least six months, the nurses who gave informed consent to take part in the study, nurses with a valid license (licensed nurse), and nurses who were working in maternity wards.

\section{Exclusion criteria or avoidance criteria}

Exclusion criteria of the study were; nurses who were sick during the data gathering period, nurses who failed to give informed consent during the study, nurses who have working experience of less than six 
months, and nurses' students as well as intern nurses.

\section{Sample Size and Sampling Technique}

The sample was computed by using the formulae as structured by Fisher in $1965, n=Z^{2} P(1-$

$P) / E^{2}$ Where,Zis the $Z$ value for the confidence level of $95 \%, d$ is the standard error of $5 \%$, pis the value for the extent of $26.6 \%$ (12).

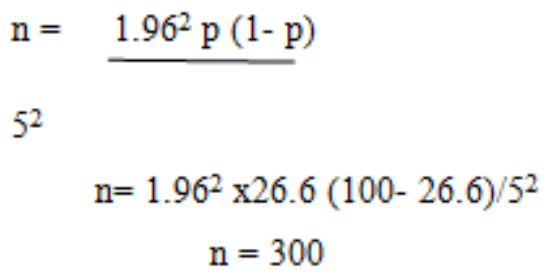

Finite population correction for proportion was adopted from (5) as $n f=n /(1+n / N)$

Where,

$\mathrm{nf}=$ Desired sample size,

$\mathrm{n}=$ Computed sample size and

$\mathrm{N}=$ approximated population in the area understudy.

$$
\begin{gathered}
\frac{300}{\mathrm{nf}=1+300 / 250} \\
=136
\end{gathered}
$$

Subsequently, the sample size increased by $10 \%$ of study dropouts which gave a total of 150

\section{Sampling technique}

Singida region was purposively selected to be the area understudy in Tanzania. One district (Singida urban) was selected by simple random sampling from the seven districts of Singida Region. Three staged multi-stage cluster sampling technique was used to obtain study participants. In first stage random sampling, all wards (16 wards) in Singida urban (municipality) were listed and by the use of purposive random sampling three wards (Ipembe, Mandewa, and Misuna) were picked since are the only wards with two big health facilities in Singida municipality.

During second stage sampling two health facilities (Singida Region Referral Hospital and Sokoine Health Center) were conveniently selected from six health facilities because had large number of nurses compared to other health facilities found in Singida municipality. The third stage sampling was simple random sampling technique used to obtain study participants. At each health facility nurses were interviewed for working experience, those who were worked for at least six months and gave consent to participate in the study were enrolled. 


\section{Data analysis}

The data analysis employed both descriptive and inferential statistical analysis. Descriptive data analysis was used to determine frequencies and percentages of Sociodemographic characteristics of the study respondents. Chi-square and cross-tabulation were adopted to determine the relationship between categorical variables. Inferential data analysis served to determine the extent of association between variables. A confidence interval $(\mathrm{Cl})$ was set at $95 \%$ with a significance level of $5 \%$. Statistical Package for Social Sciences (SPSS) software program version 23 was used for data entry, processing, and analysis. Findings were presented in tables by frequencies (n), percentages (\%), Odds Ratio (OR), Adjusted Odds Ratio (ARO), and $\mathrm{p}$-values at $95 \% \mathrm{Cl}$ of demonstrating significance relationship and or association between variables.

\section{Results}

\section{Sociodemographic Characteristics of the Study Respondents}

The results uncovered that most of the respondents' ages from 20 to 32 years which was $68.7 \%(n=103)$. Furthermore, study findings showed that most of the respondents'58.7\% $(n=88)$ were female and the mean age range of the study respondents was 26 years and $68.7 \%(n=103)$ were within the age group of 20-32 years. The study respondents $42.7 \%(n=64)$ were assistant nurse officers (diploma holders) and $29.3 \%(n=44)$ were nurse and midwife officers, as well as $28 \%(n=42)$ had a certificate in nursing. Also, $61.3 \%(n=92)$ works at Singida Regional Referral Hospital; notwithstanding that, further Sociodemographic qualities are depicted in Table 1. 
Table 1

Sociodemographic characteristics of study respondents $(n=150)$

\begin{tabular}{|c|c|c|}
\hline Variables & $\mathbf{n}$ & $\%$ \\
\hline Age Group & 103 & 68.7 \\
\hline $20-32$ & 32 & 21.3 \\
\hline $33-45$ & & \\
\hline $46-58$ & 15 & 10.0 \\
\hline Gender & 62 & 41.3 \\
\hline $\begin{array}{l}\text { Male } \\
\text { Female }\end{array}$ & 88 & 58.7 \\
\hline Marital Status & 54 & 36.0 \\
\hline Single & 93 & 62.0 \\
\hline Married & 2 & 1.3 \\
\hline Widower & 1 & 0.7 \\
\hline Religion & 37 & 24.7 \\
\hline Muslim & 112 & 74.7 \\
\hline $\begin{array}{l}\text { Christian } \\
\text { Others }\end{array}$ & 1 & 0.6 \\
\hline Level of Education Attained & 107 & 71.3 \\
\hline $\begin{array}{l}\text { College } \\
\text { University }\end{array}$ & 43 & 28.7 \\
\hline Professional Qualifications & 44 & 29.3 \\
\hline $\begin{array}{l}\text { Nurse and midwife officers } \\
\text { Assistant nurse officer }\end{array}$ & 64 & 42.7 \\
\hline Enrolled nurse & 42 & 28.0 \\
\hline Residence & 68 & 45.3 \\
\hline Urban & 82 & 54.7 \\
\hline Semi-urban & & \\
\hline Source: Field Data (2020) & & \\
\hline
\end{tabular}

Page $7 / 19$ 


\begin{tabular}{|c|c|c|}
\hline Korintplgquealth Facility & n 58 & $\% 8.7$ \\
\hline $\begin{array}{l}\text { Health center } \\
\text { Hospital }\end{array}$ & 92 & 61.3 \\
\hline Source: Field Data (2020) & & \\
\hline
\end{tabular}

\section{Level of Practice on the use of Partograph among nurses}

The results uncovered that the greater part of respondents $61.3 \%(n=92)$ who were working in the maternity department at SRRH and Sokoine health center had low a level of practice on the usage of partograph charts accessible in the wards on the delivery of nursing care. Besides, $38.7 \%(n=58)$ of nursing caretakers among 150 nurses who participated in the research had a high level of practice on the use of partograph during the delivery of nursing care in SRRH and Sokoine health center in Singida Municipality.

Table 2

\begin{tabular}{|c|c|c|}
\hline \\
\hline \multicolumn{2}{|c|}{$\begin{array}{lll} & \\
\text { usage among nurses }(n=15 \\
\text { /ariables } \quad n\end{array}$} & usage among nurses $(n=150)$. \\
\hline & \multicolumn{2}{|c|}{ Level of practice 92} \\
\hline Low practice & 58 & 38.7 \\
\hline \multicolumn{3}{|l|}{ High practice } \\
\hline \multicolumn{3}{|l|}{ Total } \\
\hline
\end{tabular}

\section{Factors Influencing Levels Of Practice On Partograph Utilization}

Among 150 nurses, nurses whose age were between 20 to 32 years, $46.1 \%(n=47)$ had a high level of practice while $53.9 \%(n=55)$ had a low level of practice on partograph utilization, age group between 33 to $45 y$ years, $21.9 \%(n=7)$ had a high level of practice while $78.1 \%(n=25)$ had a low level of practice on partograph utilization and those with the age category of 46 to 58 years, 25.0\% $(n=4)$ had a high level of 
practice while $75.0 \%(n=12)$ had a low degree of practice on partograph utilization this implied that age has influences on partograph use among nurses in Singida municipality.

Moreover, study findings depicted that nurse and midwife officers $81.8 \%(n=36)$ had a high level of practice while $18.2 \%(n=8)$ had a low level of practice on partograph utilization. The number of assistant nurse officers, $20.3 \%(n=13)$ had a high level of practice while $79.7 \%(n=51)$ had a low level of practice on the partograph use and among the enrolled nurses, $21.4 \%(n=9)$ had a high level of practice while $78.6 \%(n=33)$ had a low level of practice on the use of partograph among nurses which showed that professional qualifications influenced partograph use.

On the other hand, nurses who had university education, $83.3 \%(n=35)$ had a high level of practice while only $16.7 \%(n=7)$ had a low level of partograph usage during checking progress and monitoring labour, fetal and maternal condition. Likewise, among nurses who reached the institute level, $21.3 \%(n=23)$ had a high level of practice while $78.7 \%(n=85)$ had a low level of practice on the partograph usage, this uncovered that education level influences partograph use among nurses in Singida municipality.

Furthermore, 82 nurses who lived in semi-urban $47.6 \%(n=39)$ had a high level of practice while $52.4 \%$ ( $n$ $=43$ ) had a low level of practice on partogram use contrasted with nurses living in urban where $27.9 \%$ ( $\mathrm{n}$ $=19)$ had a high level of practice on partograph utilization while $72.1 \%(n=49)$ had a low level of practice on partograph utilization.

It was evident that gender had an influence on the level of practice on partograph usage among nurses in Singida municipality as results uncovered that among male $48.4 \%(n=30)$ had a high level of practice while $51.6 \%(n=32)$ had a low level of practice on partograph use on the provision of nursing services. Likewise, among female results depicted that $31.8 \%(n=28)$ had a high level of practice on the partograph use while $68.2 \%(n=60)$ had a low level of practice on partograph usage among nurses in Singida municipality. Other factors influencing the utilization of partograph have been summarized in Table 3. 
Table 3

Factors influencing the level of practice on the utilization of partograph $(n=150)$

\begin{tabular}{|c|c|c|}
\hline \multirow[t]{2}{*}{ Variables } & \multicolumn{2}{|c|}{ Level of practice } \\
\hline & Low practice & High practice \\
\hline \multirow{2}{*}{$\begin{array}{l}\text { Age Category } \\
20 \text { to } 32 y r s\end{array}$} & $55(53.9 \%)$ & $47(46.1 \%)$ \\
\hline & $25(78.1 \%)$ & $7(21.9 \%)$ \\
\hline \multicolumn{3}{|l|}{33 to $45 y r s$} \\
\hline 46 to $58 \mathrm{yrs}$ & 12(75.0\%) & $4(25.0 \%)$ \\
\hline \multirow{3}{*}{$\begin{array}{l}\text { Gender } \\
\text { Male }\end{array}$} & $32(51.6 \%)$ & $30(48.4 \%)$ \\
\hline & 6000201 & \\
\hline & $60(68.2 \%)$ & 28(31.8\%) \\
\hline \multirow{4}{*}{$\begin{array}{l}\text { Religion } \\
\text { Muslim } \\
\text { Christian } \\
\text { Others }\end{array}$} & $24(64.9 \%)$ & $13(35.1 \%)$ \\
\hline & $68(60.7 \%)$ & $44(39.3 \%)$ \\
\hline & & \\
\hline & $0(0.00 \%)$ & $1(100.0 \%)$ \\
\hline \multirow{2}{*}{$\begin{array}{l}\text { Marital Status } \\
\text { Single }\end{array}$} & $28(51.9 \%)$ & $26(48.1 \%)$ \\
\hline & $61(65.6 \%)$ & $32(34.4 \%)$ \\
\hline Married & $2(100.0 \%)$ & $0(0.00 \%)$ \\
\hline Widower & $1(100.0 \%)$ & $0(0.00 \%)$ \\
\hline \multirow{2}{*}{$\begin{array}{l}\text { Education Level } \\
\text { College }\end{array}$} & $85(78.7 \%)$ & $23(21.3 \%)$ \\
\hline & $7(16.7 \%)$ & 35(83.3\%) \\
\hline \multirow{3}{*}{$\begin{array}{l}\text { Professional Qualifications } \\
\text { Nurse and midwife officers } \\
\text { Assistant nurse officer } \\
\text { Enrolled nurse }\end{array}$} & $8(18.2 \%)$ & $36(81.8 \%)$ \\
\hline & $37(57.8 \%)$ & $27(42.2 \%)$ \\
\hline & $25(59.5 \%)$ & $17(40.5 \%)$ \\
\hline \multirow{2}{*}{$\begin{array}{l}\text { Residence } \\
\text { Urban } \\
\text { Semi-Urban }\end{array}$} & $49(72.1 \%)$ & 19(27.9\%) \\
\hline & $43(52.4 \%)$ & $39(47.6 \%)$ \\
\hline
\end{tabular}




\begin{tabular}{lcc|} 
Working Health Facility & $39(67.2 \%)$ & $19(32.8 \%)$ \\
Health center & $53(57.6 \%)$ & $39(42.4 \%)$ \\
Hospital & & \\
\cline { 2 - 2 }
\end{tabular}

\section{Relationship between Factors Influencing level of Practice of Partograph Utilization and Level of Practice}

Concerning the relationship between age category of study respondents and level of practice on partograph usage, results depicted that there is a significant relationship between age group and level of practice among nurses as proven by $\left(X^{2}=7.427 ; p<0.05\right)$. Among 150 study respondents, nurses whose age were between 20 to 32 years, $46.1 \%(n=47)$ had a high level of practice while $53.9 \%(n=55)$ had a low level of practice on partograph utilization, age group between 33 to $45 y e a r s, 21.9 \%(n=7)$ had a high level of practice and $78.1 \%(n=25)$ had a low level of practice on partograph utilization and nurses with the age category of 46 to 58 years, $25.0 \%(n=4)$ had a high level of practice while $75.0 \%(n=12)$ had a low level of practice on partograph utilization.

In light of the research among 150 respondents, results indicated that nurse and midwife officers $81.8 \%$ $(n=36)$ had a high level of practice while $18.2 \%(n=8)$ had a low level of practice on partograph usage. Between the assistant nurse officers, 20.3\% $(n=13)$ had a high level of practice while $79.7 \%(n=51)$ had a low level of practice on the partograph usage and among the enrolled nurses, $21.4 \%(n=9)$ had a high level of practice while $78.6 \%(n=33)$ had a low level of practice on partograph usage. The chi-squared test indicated that there is a significant relationship between professional qualifications and level of practice on the partograph usage among nurses $\left(X^{2}=49.835 ; p<0.05\right)$.

Concerning level of education between nurses who reached the university level, 83.3\% $(n=35)$ had a high level of practice while only $16.7 \%(n=7)$ had a low level of practice on partograph usage in Singida region. Additionally, among nurses who reached college or institutional level, 21.3\% $(n=23)$ had a high level of practice while $78.7 \%(n=85)$ had a low level of practice on the partograph use. The computation of the chi-squared test findings depicted that there is a statistically significant relationship between the level of education and practice on partograph usage among nurses in Singida municipality $\left(X^{2}=49.704\right.$; $p<0.05)$.

Besides; among 150 study participants, 82 nurses live in semi-urban where $47.6 \%(n=39)$ had a high level of practice while $52.4 \%(n=43)$ had a low level of practice on partograph usage contrasted with those who live in urban which showed that $27.9 \%(n=19)$ had a high level of practice on partograph usage while $72.1 \%(n=49)$ had a low level of practice on the use of partograph. The chi-squared test showed that there is a statistically significant relationship between residence and level of practice on partograph usage among nurses in Singida municipality $\left(X^{2}=6.034 ; p<0.05\right)$. 
It was evident that gender had an influence on the level of practice on partograph usage among nurses in Singida region as results uncovered that $48.4 \%(n=30)$ males had a high level of practice and $51.6 \%(n=$ 32) had a low level of practice on partograph use on the provision of nursing services. Additionally, among females results depicted that $31.8 \%(n=28)$ had a high level of practice on the partograph utilization while $68.2 \%(n=60)$ had a low level of practice on the usage of partograph in Singida municipality. Results showed that there is a statistical significance $\left(X^{2}=4.211 ; p<0.05\right)$. Furthermore; other independent variables such as religion, marital status, and working health facility had no statistical significant relationship with the level of practice on the usage of the partograph among nurses in Singida municipality. 
Working Health Facility $\quad 39(67.2 \%) \quad 19(32.8 \%) \quad X^{2}=1.392$

Health center

Hospital

$53(57.6 \%) \quad 39(42.4 \%)$

$P=0.238$

\section{Association between Factors Influencing Practice Level on Partograph Utilization and Level of Practice}

After control of different variables, the study respondents who were found to have a bachelor's degree in nursing and midwifery were more times likely to have high a level of practice on partograph utilization as compared to other education levels (University OR $=18.478, p=0.001,95 \% \mathrm{Cl}: 7.268 ; 46.981$ ). When combined with different variables the power was adjusted to (AOR $=16.757, p=0.001 ; 95 \% \mathrm{Cl}$ : 6.394 ; 43.915). Additionally, after control of other variables the nurse and midwife officers were more times likely to have high practice on partograph use as compared to other professional qualifications (Nurse and midwife officers AOR $=8.323 ; p=0.004 ; 95 \% \mathrm{Cl}$ : 0.098; 0.642) in Singida municipality. Further information is condensed in Table 5. 
Table 5

Logistics regression analysis of the relationship between socio-demographic data and degree of practice on partograph utilization $(\mathrm{n}=150)$.

\begin{tabular}{|c|c|c|c|c|c|c|c|c|}
\hline \multirow[t]{2}{*}{ Variable } & \multirow[t]{2}{*}{ OR } & \multirow{2}{*}{$\begin{array}{l}\mathrm{p}- \\
\text { value }\end{array}$} & \multicolumn{2}{|l|}{$95 \% \mathrm{Cl}$} & \multirow[t]{2}{*}{ AOR } & \multirow{2}{*}{$\begin{array}{l}\mathrm{p} \text { - } \\
\text { value }\end{array}$} & \multicolumn{2}{|c|}{$95 \% \mathrm{Cl}$} \\
\hline & & & Low & High & & & Low & High \\
\hline Gender & 0.498 & 0.041 & 0.255 & 0.973 & 1.056 & 0.9 & 0.451 & 2.47 \\
\hline \multicolumn{9}{|l|}{ Male(Ref) } \\
\hline \multicolumn{9}{|l|}{ Female } \\
\hline Education Level & 18.478 & 0.000 & 7.268 & 46.981 & 16.757 & 0.000 & 6.394 & 43.915 \\
\hline \multicolumn{9}{|l|}{ College(Ref) } \\
\hline \multicolumn{9}{|l|}{ University } \\
\hline Residence & 2.339 & 0.015 & 1.180 & 4.657 & 1.485 & 0.351 & 0.647 & 3.407 \\
\hline \multicolumn{9}{|l|}{ Urban(Ref) } \\
\hline \multicolumn{9}{|l|}{ Semi-urban } \\
\hline Age Category & 0.390 & 0.123 & 0.118 & 1.391 & 1.154 & 0.826 & 0.32 & 4.16 \\
\hline $20-32$ years & 1.190 & 0.808 & 0.291 & 4.867 & 1.905 & 0.396 & 0.430 & 8.447 \\
\hline \multicolumn{9}{|l|}{$33-45$ years } \\
\hline \multicolumn{9}{|l|}{ 46-58years(Ref) } \\
\hline $\begin{array}{l}\text { Professional } \\
\text { Qualifications }\end{array}$ & 7.568 & 0.006 & 0.117 & 0.697 & 8.323 & 0.004 & 0.098 & 0.642 \\
\hline \multicolumn{9}{|l|}{$\begin{array}{l}\text { Nurseand midwife } \\
\text { officer }\end{array}$} \\
\hline \multicolumn{9}{|l|}{ Assistant nurse officer } \\
\hline Enrolled nurses(Ref) & & & & & & & & \\
\hline
\end{tabular}

\section{Discussion}

This study entailed at assessing the level of practice and factors influencing partograph utilization.

\section{Level of Practice on Partograph Utilization Among Nurses}

The findings found that most of the study respondents $61.3 \%(n=92)$ had a low level of practice on using partograph to deliver health care among nurses in Singida municipality. This implied that even if they 
learned about the usage of partograph in classrooms, health institutions and workshops or seminars data discovered that there is a gap between knowledge and practice on the utilization of partograph for monitoring the progress of labour as well as maternal and fetal condition. The probable cause could be discussed in this study to be due to residence, education level, age, gender, and professional qualifications among nurses in the Singida municipality.

These findings differ with those found by Bazirete (13) whereas data depicted that $58.8 \%$ of the study respondents were found to have low level practice in utilizing partograph. The difference in findings in these two studies is probably due to different study areas. Moreover, the results of this study were different from those conducted in Kenya whereas data showed that $55.5 \%$ of study respondents had a lower level of practice on partograph utilization (5). Furthermore, findings from this study were low compared to the results of a study which was conducted in India of which data depicted that majority of the study respondents (86.67\%)had a low level of practice on partograph utilization(14).

\section{Factors influencing the level of practice on the utilization of the partograph}

The study results show that there is a statistically significant relationship between age group and level of practice among nurses $p=0.024$. This implied that the age of the respondents influenced the level of practice on the partograph usage in Singida municipality. The probable reason to be discussed in this study is due to forgetfulness because the majority of respondents with age group between 20 to 30 years had a high level of practice on partograph utilization compared to other age groups. Also, this kind of results is similar to the study conducted in Ethiopia of which data showed that age was statistically significantly associated with the level of partograph use $p<0.05(15)$.

The findings discovered that there is a statistically significant relationship between professional qualifications and level of practice on partograph use among nurses $p>0.01$. The majority of study respondents who had a high level of practice were nurse officers followed by nurse officer midwives compared to other professional qualifications. The probable reason behind to be discussed in this study is due to the level of education and knowledge on partograph utilization. This kind of statistical relationship is similar to that found by(12)who studied the level of partograph usage and its related factors among obstetrics care workers at health facility northwest Ethiopia $p>0.01$.

The study's findings have revealed that the majority of nurses who had university education had a high level of practice on partograph use in Singida municipality $p>0.01$. This implied that the nurse officers and nurse officer midwives learned about the utilization of partograph in the university were knowledgeable and had enough skills on partograph utilization. The probable cause could be discussed in this study to be due to the level of education as well as competence and skills on the utilization of partograph for monitoring and managing labour progress, fetal and maternal conditions. These kinds of results are similar to the study done at Ethiopia on level of partograph usage and its related elements among obstetricians in northwest Ethiopia which showed that professional qualification was significantly associated with the level of practice on the utilization of partograph $p<0.05(12)$. 


\section{Conclusion}

The vast majority of the study respondents had a low level of practice on partograph usage on the provision of health services among nurses in Singida municipality; this could endanger both maternal and fetal health. The probable causes to be discussed are due to educational level, professional qualifications, residence, and age in Singida municipality. Moreover, close supervision, on the job training, seminar, and staff motivation should be reviewed to ensure the quality of health care services by proper utilization of partograph among nurses in Singida municipality.

\section{Limitations}

Basing on this study, the limitation to be highlighted are such as the cause - effect relationship is difficult to establish, the data was gathered by using a self-administered questionnaire and it could be subjected to social desirability bias and the findings are from Singida municipality hence cannot be generalized to the whole population in Tanzania.

\section{Abbreviations}

HESLB

Higher Education Students' Loans Board

MMR

Maternal mortality ratio

SRRH

Singida Regional Referral Hospital

UDOM

University of Dodoma

WHO

World Health Organization

\section{Declarations}

\section{Ethical Approve and Consent for Participation}

The Ethical clearance approval for conducting this study was given by Ethical the University of Dodoma, Institution Research Review Committee, Municipal Director, Regional Medical Officer, District Medical Officer, and Hospital Medical in charges. Written informed consent was asked from every study respondent. Privacy and confidentiality were guaranteed as well as autonomy was watched plainly because neither the study respondents' names nor of those health facilities involved were requested on the questionnaire.

\section{Consent for Publication}


Not applicable

\section{Availability of Data and Material}

On reasonable request the datasets used and analyzed during this study are available from the corresponding author.

\section{Competing Interests}

The authors declared that they don't have competing interests

\section{Funding}

The authors have shown that they haven't financial relationship relevant to this manuscript to disclose.

\section{Authors' Contributions}

D. P. originated the study and contributed much tostudy design, data collection, and data analysis. W. M, F. M and A. J contributed on close monitoring and directing the conceptualization of the study, an indepth review of the study design, data analysis, and manuscript development. All authors approve the submission of the final manuscript.

\section{Acknowledgement}

I thank and acclaim to my Almighty God for helping me through the troublesome occasions, satisfying my needs, and for keeping me alive and healthy to do this research. I would like to acknowledge and thank my supervisor Mr. Walter C. Millanzi for his close supervision and unmeasurable support as well as tolerance. Also, much appreciation to my course coordinator Dr. Fabiola Moshi and Angel Joho who guided me on the whole process of conducting this investigation.

I might want exceptionally to express gratitude towards UDOM Research and Publications committee for approving and providing ethical clearance before conducting this study.I am grateful to the Municipality Director, District Medical Officer and Medical Officer in charge for allowing me for data collection as well as for their good cooperation.

I express much thanksgiving to Higher Education Students Loans Board (HESLB) for providing me funds for conducting this study.

\section{References}

1. Zelellw DA, Tegegne TK. Level of partograph utilization and its associated factors among obstetric caregivers at public health facilities in East Gojam Zone, Northwest Ethiopia. 2018;07:1-13. Available from: http://dx.doi.org/10.1371/journal.pone.0200479 
2. Sigounas G. HRSA Maternal Mortality Summit: U . S . Department of Health and Human Services. 2019;

3. Messages K, Recommendations G, Care RA. WHO Recommendations on Antenatal Care for a Positive Pregnancy Experience: Summary Highlights and Key Messages from the World Health Organization 's 2016 Global Recommendations for Routine Antenatal Care. 2018;10(January):1-10.

4. Opiah MM, Ofi AB, Essien EJ, Monjok E. Knowledge and Utilization of the Partograph among Midwives in the Niger Delta Region of Nigeria. 2012;16(March):125-32.

5. Githae, Mbisi A, Jo B. Utilization of Partograph in the Management of Women in Labor among Nurses Working in Embu County , Kenya. 2019;1-13.

6. Dingana TN, Angwafo FF. Knowledge and utilization of the partograph: A cross-sectional survey among obstetric care providers in urban referral public health institutions in northwest and southwest. 2017;71:1-14.

7. Bazirete O. Utilization of Partogram among Nurses and Midwives in Rwamagana health facilities in the eastern province of Rwanda. 2014;(August).

8. Kaur R. A study to assess the knowledge regarding partograph among staff nurses. 2019;5(2):7881.

9. Konlan KD, Kombat JM, Wuffele MG, Aarah-bapuah M. Knowledge and attitudes of midwives on the use of the partogram: a study among midwives in the Tamale Metropolis. Matern Heal Neonatol Perinatol. 2016;4-7.

10. Mbanga EN. Annual Assessment Report External Hospital Performance Assessment for Regional Referral Hospitals. 2018;(October).

11. Polit F\&, Beck C. Nursing Research: Principles and Methods. 7 ed. Philadephia:Lippincott Williams \&Wilkins; 2003. 758 p.

12. Zelellw DA, Tegegne TK. Level of partograph utilization and its associated factors among obstetric caregivers at public health facilities in East Gojam Zone, Northwest Ethiopia. 2018;07:1-13.

13. Bazirete O. Utilization of Partograph among Nurses and Midwivies in Rwamagana health facilities in the eastern province Rwanda. 2014;(August).

14. Varnish K. Knowledge and Practice on Partograph. 2014;1(2):10-3.

15. Hailu T, Nigus K, Gidey G, Hailu B, Moges Y. Assessment of partograph utilization and associated factors among obstetric care givers at public health institutions in central. BMC Res Notes [Internet]. 2018;1-6. Available from: https://doi.org/10.1186/s13104-018-3814-7 